\title{
Article \\ Effect of Machining Limiting Factors on Drilling Progress during Spark Assisted Chemical Engraving (SACE): General Trends
}

\author{
Jana D. Abou Ziki ${ }^{1, *(1)}$ and Rolf Wüthrich ${ }^{2,3}$ \\ 1 Department of Mechanical and Manufacturing Engineering, Ontario Tech University, \\ Oshawa, ON L1G 0C5, Canada \\ 2 Department of Mechanical, Industrial and Aerospace Engineering, Concordia University, \\ Montreal, QC H3G 1M8, Canada; rolf.wuthrich@concordia.ca \\ 3 Department of Chemical and Materials Engineering, Concordia University, \\ Montreal, QC H3G 1M8, Canada \\ * Correspondence: jana.abouziki@ontariotechu.ca
}

Citation: Abou Ziki, J.D.; Wüthrich, R. Effect of Machining Limiting Factors on Drilling Progress during Spark Assisted Chemical Engraving (SACE): General Trends. Ceramics 2021, 4 , 618-627. https://doi.org/10.3390/ ceramics 4040044

Academic Editors: Antonio Riveiro Rodriguez and Gilbert Fantozzi

Received: 29 July 2021

Accepted: 1 November 2021

Published: 5 November 2021

Publisher's Note: MDPI stays neutral with regard to jurisdictional claims in published maps and institutional affiliations.

Copyright: (c) 2021 by the authors. Licensee MDPI, Basel, Switzerland. This article is an open access article distributed under the terms and conditions of the Creative Commons Attribution (CC BY) license (https:// creativecommons.org/licenses/by/ $4.0 /)$.

\begin{abstract}
Spark Assisted Chemical Engraving (SACE) is a micro-machining technology for nonconductive materials, mainly glass, based on thermal assisted etching. Generally, during SACE, drilling proceeds at a fast rate reaching $100 \mu \mathrm{m} / \mathrm{s}$ for the first $100 \mu \mathrm{m}$ and then it slows down for depths higher than $300 \mu \mathrm{m}$. While several techniques have been proposed to establish faster drilling, they mainly rely on tuning the machining parameters to enhance the machining performance. However, with this approach machining parameters need to be constantly tuned to achieve certain machining performance depending on the size of the tool and the features needed. Therefore, this necessitates further work to enhance understanding regarding the SACE machining process fundamentals in order to enhance machining speed and quality. Since SACE is a thermal assisted etching process, both local heating and flushing of electrolyte in the machining zone are required. However, to the authors' knowledge there is not any study that attempts to analyze the effect of each of these machining limiting factors on the machining performance. This work attempts to clarify the effect of each flushing and heating on the drilling progress for hole depths higher than 100 microns. It therefore provides a deeper understanding of the fundamentals of the SACE machining process.
\end{abstract}

Keywords: glass micro-drilling; Spark Assisted Chemical Engraving; local heating and flushing; machining progress

\section{Introduction}

Currently, with the evolution of technology and the growing need of miniaturization, the interest in developing micro-fabrication methods for different materials has been growing. Among these materials are ceramics and glass, due to their unique properties such as high temperature and chemical resistance as well as their biocompatibility. Glass is also the material of choice when it comes to optical applications. While there exist different methods to machine glass on the micro-scale, including thermal, mechanical, and chemical methods, such methods have limitations, including the achieved surface quality, machining speed, setup affordability and complexity. Spark Assisted Chemical Engraving (SACE) is a relatively new nonconventional machining technology for non-conductive materials, mainly glass.

In SACE, the work-piece and two electrodes are dipped in an alkaline solution. Upon applying a voltage between the tool and counter-electrode, bubbles form in the tool vicinity and they coalesce into a gas film that isolates the tool tip from the surrounding electrolyte. The current passes through the tool tip in the form of high energy electrical discharges. These discharges lead to high local temperature in the tool's vicinity reaching $500-600{ }^{\circ} \mathrm{C}$. This was quantified by using thermocouples [1], by performing spectroscopic measurements [2], and based on estimating the glass viscosity in the machining zone [3]. Later, 
a heat transfer model was developed to estimate this temperature [4]. The heat source from the tool was considered to be located on the glass surface. By matching the evolution of the simulated temperature gradient with the size of machined structures (holes), the temperature needed to machine glass by SACE was estimated to be around $600{ }^{\circ} \mathrm{C}$.

The major SACE machining modes are gravity-feed and constant velocity-feed. In gravity-feed drilling, the tool is made to push into the substrate under the action of its weight. Hence, machining proceeds under the action of a constant force. In constant velocity-feed, the tool is moved downwards towards the substrate at a constant feed-rate during machining. Each of the two methods has its advantages and limitations. In gravityfeed the material removal rate is high (reaches around $100 \mu \mathrm{m} / \mathrm{s}$ ) for depths up to about 200-300 $\mu \mathrm{m}$ and is significantly reduced to a few micrometers per second for higher depths where heat affected zones form [5]. In gravity-feed machining, the tool, or heat source, is always in contact with the substrate which accelerates machining for shallow depths (around 100 microns). However, drilling slows down for higher depths as electrolyte cannot be flushed into the machining zone. Constant velocity-feed drilling has the advantage of less frequent contact between the tool and glass surface but is limited by the range of allowable tool feed-rates and is normally applied up to around $300 \mu \mathrm{m}$ depth. In fact, for this machining mode drilling progress is determined by the etching rate relative to tool speed. If the etching rate is higher than tool speed a tool-substrate gap forms allowing flushing, otherwise this mode will be similar to gravity-feed. When a gap exists, machining can either progress for moderate gap size or slow down for high gaps. Studies showed that for a gap higher than $20 \mu \mathrm{m}$ the heat source will be far from the surface, hence limiting machining [6].

Attempts have been made to enhance machining rate and quality. These include modifying the tool shape, including using flat sidewall-flat front tool [7], side-insulated tool [8], drill bit [9], helical tool with high-speed rotation [10], internally structured tube electrode [11] and spherical tip tool [12]. Other attempts include using pulsed voltage [13,14], modifying the electrolyte constituents [15,16], adding tool motion such as rotation [17] and orbital motion [18], adding tool vibration [19], vibrating electrolyte [20] and doing magnetic assisted field machining [21,22]. It was also shown that deeper holes could be established through adding pressurized electrolyte flow [23] and by applying counter-resistant feeding through reducing the magnitude of contact force between the tool and substrate as drilling progresses [24]. Furthermore, basic algorithms based mainly on the tool-substrate contact force were applied to enhance machining rate and increase the structure aspect ratio, such as adjusting the machining voltage upon detecting a force signal [25]. While these approaches generally enhanced machining rate, depth or quality for specific machining conditions, there is no study that quantifies trends in terms of the effect of each of the machining limiting factors, i.e., heating and flushing, on the machining progress. In this paper, we study and present such trends. The effect of heating and flushing on machining progress is evaluated by considering the recorded reduction in drilling time for holes deeper than 100 microns. This work serves to enhance the understanding of the importance and precedence of heating and flushing in terms of each one's effect on machining progress. We believe that this work enhances the fundamental knowledge about the SACE machining process, hence allowing enhancement of SACE machining capabilities.

\section{Experimental Setup}

The machining setup is composed of a machining head which holds the tool and that is guided in the Z-direction by a linear precision stage with $1 \mu \mathrm{m}$ resolution (Figure 1). The head, composed of a flexible structure, contains a voice coil actuator that can move the structure in both upwards and downwards Z-directions. It also has a spindle that allows tool rotation (up to $3000 \mathrm{rpm}$ ). The head can be operated in the force sensor mode, where machining forces acting on the tool (in the upward direction) are measured by the force controller which exerts an opposite force on the structure to keep it at the same initial 
position. The force sensor can measure forces in the range of 0 to $5 \mathrm{~N}$ (signal noise is around $10 \mathrm{mN} \mathrm{rms})$.

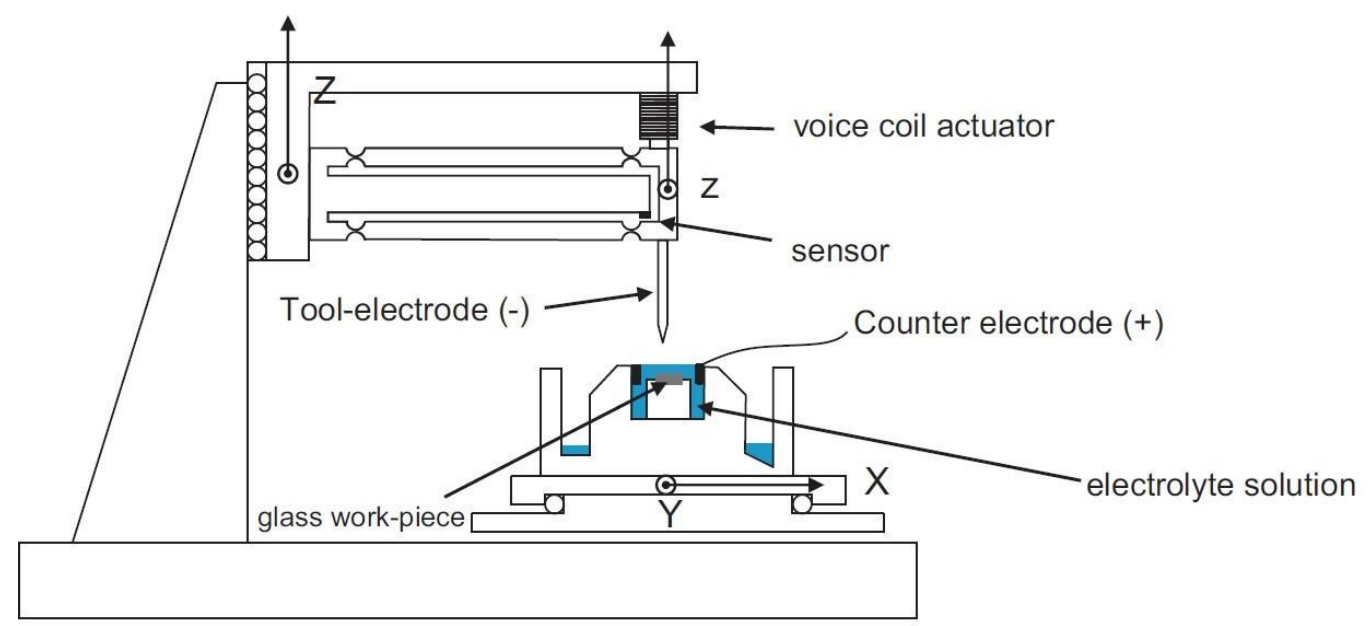

Figure 1. Sketch of the SACE machine setup which is composed of a machining head, holding the tool, guided in the Z-direction by a linear precision stage. The head contains a voice coil actuator that can move it in the Z-direction and can also hold it at a fixed z position while being in the force sensor mode. The head also has a spindle that allows tool rotation. The processing cell, mounted on the XY stage, contains the glass work-piece and allows its alignment with the tool. Reprinted from [26] with permission from Elsevier.

The processing cell, mounted on an XY stage, contains the glass work-piece where it allows aligning it with the tool. All electrolytic solutions, Sodium hydroxide $(\mathrm{NaOH})$ and Potassium hydroxide $(\mathrm{KOH})$ of different concentrations, were prepared with deionized water. The liquid level above the work-piece was controlled passively to be $1 \mathrm{~mm}$ with an overflow system, where the electrolyte losses were compensated using a micro-pump. The work-pieces were microscope glass slides (Bio Nuclear Diagnostics Inc., Toronto, ON, Canada) and cylindrical, $250 \mu \mathrm{m}$ diameter, stainless steel tools were used.

\section{Results and Discussion}

From SACE gravity-feed drilling it is known that insufficient flushing of the machining zone is responsible for the reduced material removal rate at depths higher than $200 \mu \mathrm{m}$. On the other hand, adequate local glass heating through glass-tool contact is also important for drilling to proceed well. To observe this trade-off in terms of prevalence and significance of heating and/or flushing on machining progress, some tool motion feedback algorithms were applied. The feedback signal used was the tool-substrate contact force (also called machining force). The trends were identified through measuring and comparing the drilling time for each case.

\subsection{Enhancing Surface Heating by Prolonged Tool-Surface Contact}

The first algorithm aims to stop the tool motion when a given force threshold is exceeded until the force goes back to zero (as the surface below the tool is progressively machined). For this algorithm stopping the tool motion is referred to as a counter-action. The aim of the current algorithm is to see the effect of heating on the machining progress. Therefore, a low-viscosity electrolyte $(50 \mathrm{wt} \% \mathrm{KOH})$ was chosen where flushing is less of an issue. Note that increasing the force threshold at which the counter-action takes place results in making longer contact between the substrate and the heat source, the tool, and is expected to enhance local heat transfer. The holes drilled were $400 \mu \mathrm{m}$ deep while the machining voltage was $30 \mathrm{~V}$, just above the critical voltage required to form the gas film. Figure 2 shows the results. Figure 2a shows the drilling time versus the hole number as well as the number of counter-actions (upward movements) taken when the contact 
force exceeds a threshold of $0.4 \mathrm{~N}$. Figure $2 \mathrm{~b}$ shows similar information where in this case the force threshold level is $0.8 \mathrm{~N}$. The effect of surface heating on accelerating the drilling process is witnessed by the decrease in drilling time between holes as drilling progresses and this is shown in both Figure 2a,b. Comparison of drilling times for different force thresholds (trigger levels) further supports this statement. As depicted in Figure 2, similar drilling time range ( 50 to around $400 \mathrm{~s}$ ) resulted when using low force threshold of $0.4 \mathrm{~N}$ (Figure 2a) and high threshold of $0.8 \mathrm{~N}$ (Figure $2 \mathrm{~b}$ ). However, the number of counter-actions differed. In fact, the average number of counter-actions is lower for the higher force threshold due to the more efficient work-piece heating.

\section{a)}
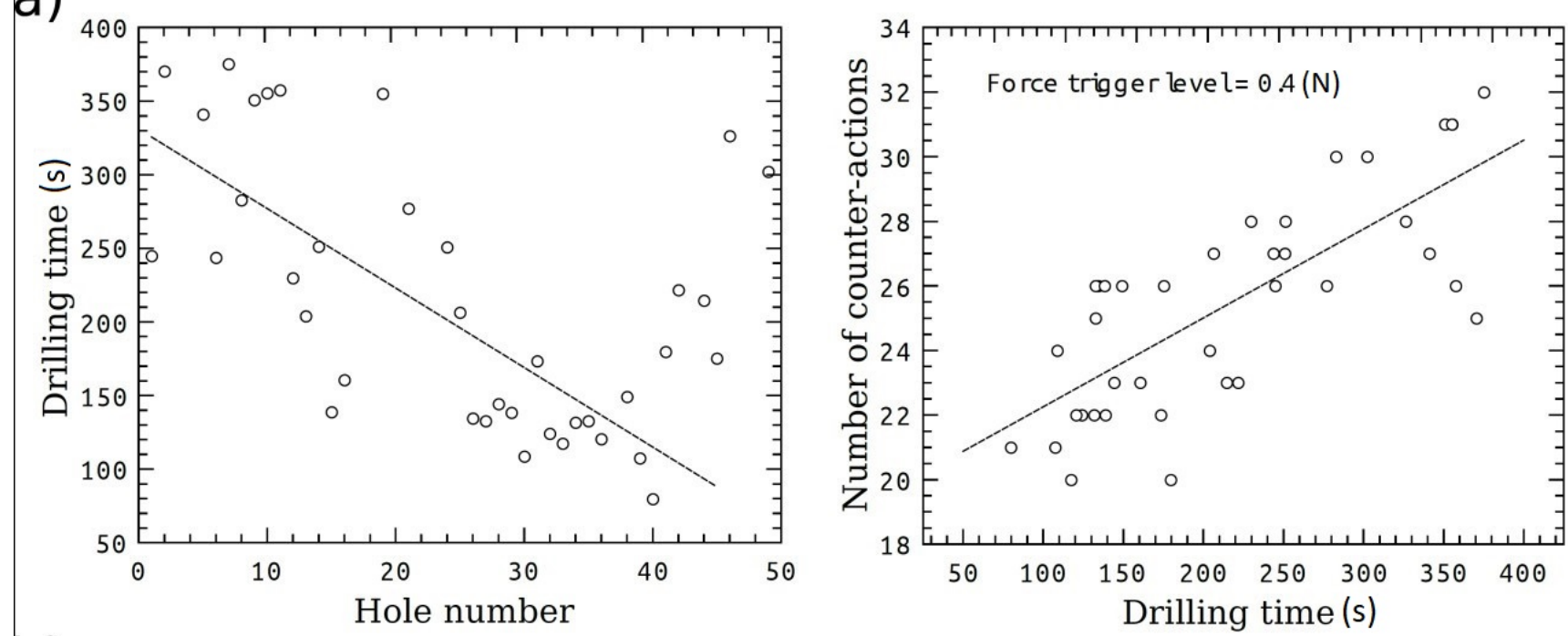

b)
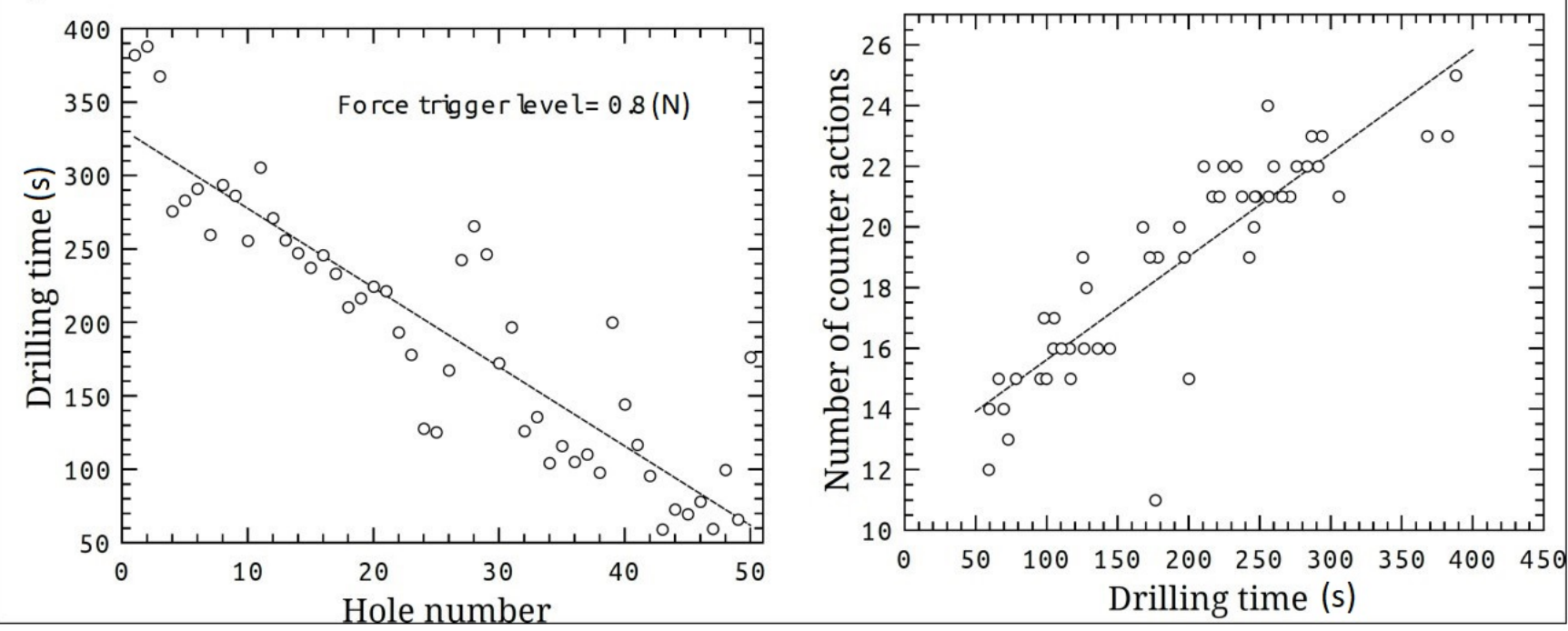

Figure 2. Drilling time in function of the hole number for an array of $400 \mu \mathrm{m}$ deep holes drilled on a single slide using $50 \mathrm{wt} \% \mathrm{KOH}$ and $30 \mathrm{~V}$, and the number of counter-actions during the time taken to drill each hole. The counter-action occurred when the force exceeded the trigger level of: (a) $0.4 \mathrm{~N}$ and (b) $0.8 \mathrm{~N}$ where the tool motion was stopped until the force went back to zero.

\subsection{Enhancing Flushing While Maintaining Heating through Creating a Machining Gap}

Based on these findings, ways to enhance the flushing while maintaining the local heat were investigated. The experiments were performed in $30 \mathrm{wt} \% \mathrm{NaOH}$ while applying $30 \mathrm{~V}$ for $250 \mu \mathrm{m}$ deep holes. To ensure frequent occurrence of contact forces (tool-substrate contact), the tool was fed at $50 \mu \mathrm{m} / \mathrm{s}$ based on the findings in [26]. This speed ensures 
tool-glass contact while machining for the applied machining conditions. For promoting flushing, the tool was moved upwards whenever a force exceeding a low threshold of $0.4 \mathrm{~N}$ was detected until the force became null, meaning that the tool was on the substrate surface. This step was followed by an upward tool motion, which is called "gap" in this text as it refers to the vertical distance created between the tool and the machined glass surface. Therefore, the counter-action for this algorithm is moving the tool upwards upon exceeding the force threshold until the force is null and then creating a machining gap between the tool and the substrate. The investigated gap ranged from 5 to $20 \mu \mathrm{m}$.

While results show that the drilling time remains the same when creating gaps up to $15 \mu \mathrm{m}$ (Figure 3), it increased dramatically for a $20 \mu \mathrm{m}$ gap. Furthermore, for every set of successively drilled holes, drilling time decreased as more holes were drilled. This transient is attributed to the heating of the electrolyte and work-piece over time. Note that while reduced drilling time was expected when creating higher gaps due to flushing the hole, the drilling time was indifferent for gaps ranging from 5 to $15 \mu \mathrm{m}$. Therefore, the present results show that the strategy of creating a tool-surface gap when the force threshold is exceeded does not efficiently contribute to local flushing.

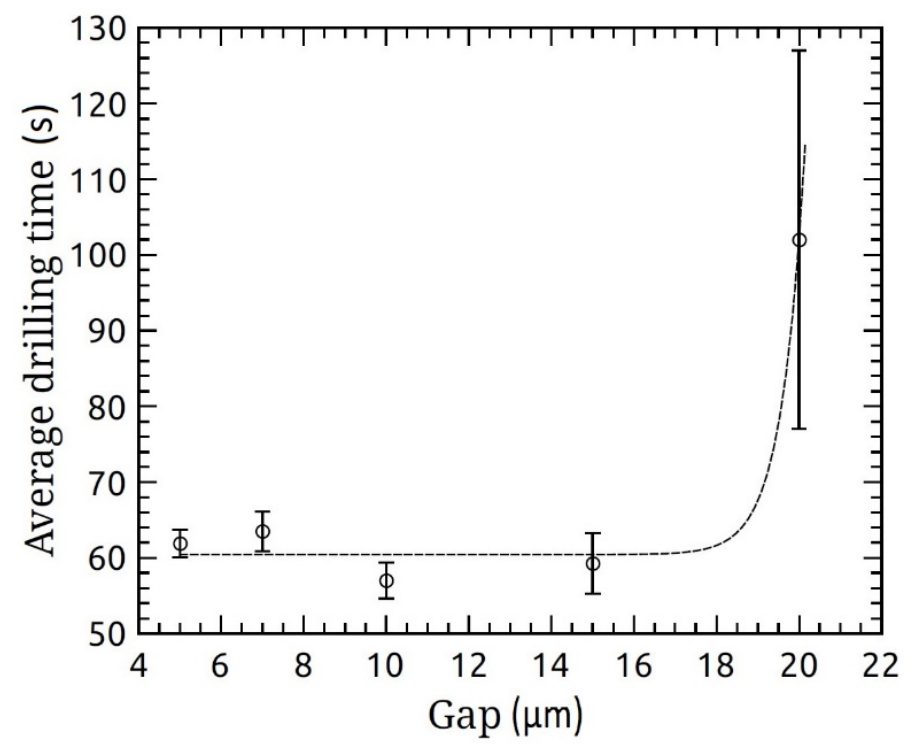

Figure 3. Average drilling time in function of the gap for $250 \mu \mathrm{m}$ deep holes. Whenever a force threshold of $0.4 \mathrm{~N}$ was exceeded, the tool was moved upwards until the force disappeared and was further moved upwards by a certain gap. The holes were drilled in $30 \mathrm{wt} \% \mathrm{NaOH}$ using $50 \mu \mathrm{m} / \mathrm{s}$ tool feed-rate and $30 \mathrm{~V}$.

A possible explanation is that the moving away from the surface does not promote local flow for the used electrolyte due to its high viscosity ( $12.6 \mathrm{cP}$ at room temperature). This strategy becomes even more counter-productive for large gaps (higher than $15 \mu \mathrm{m}$ ) as the local heat is dissipated when the tool is away from the glass surface, thus the machining zone is no longer heated efficiently.

\subsection{Enhancing the Flushing in the Machining Gap by a Delayed Tool Motion}

Based on the discussed results, the next step was checking whether adding a waiting time once a gap is created can enhance flushing. The previous algorithm was modified by adding a waiting time (called flushing time) once a $10 \mu \mathrm{m}$ gap was established, before proceeding further with drilling. The chosen gap was $10 \mu \mathrm{m}$ based on the results shown in Section 3.2. The gap was created between the tool and hole surface once a specific force threshold was exceeded as explained in Section 3.2. Therefore, for this algorithm the counter-action refers to moving the tool upwards upon exceeding a force threshold of $0.4 \mathrm{~N}$ until the force becomes null and then creating a $10 \mu \mathrm{m}$ tool-substrate gap. Afterwards, a 
certain waiting time, called flushing time, is added to allow electrolyte to flow into the hole before proceeding with machining. The flushing time ranged between 0.25 and $5 \mathrm{~s}$ while the same machining conditions ( $30 \mathrm{~V}, 50 \mu \mathrm{m} / \mathrm{s}, 30 \mathrm{wt} \% \mathrm{NaOH}$ using $50 \mu \mathrm{m} / \mathrm{s}$ ) were used as with the previous experiments. Similar drilling time was observed for flushing time up to $1 \mathrm{~s}$ (Figure 4). However, the total number of counter-actions decreased in this case, implying that the frequency of force occurrence is lower. The present results indicate that flushing can be enhanced when allowing more time to evacuate the machining zone (after establishing the gap). However, a flushing time longer than $5 \mathrm{~s}$ can significantly increase the drilling time due to heat loss, as shown on Figure 4.

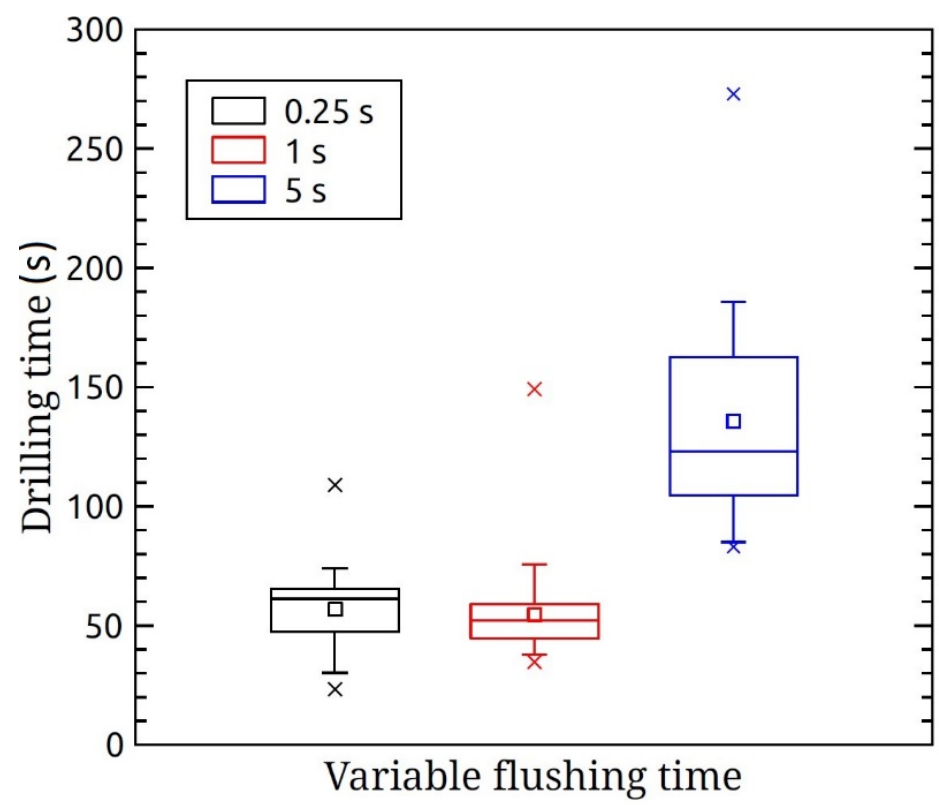

Figure 4. Drilling time for variable flushing time ranging from 0.25 to $5 \mathrm{~s}$, while using $30 \mathrm{wt}^{\mathrm{t}} \%$ $\mathrm{NaOH}$ and applying tool feed-rate and voltage of $50 \mu \mathrm{m} / \mathrm{s}$ and $30 \mathrm{~V}$, respectively, for $250 \mu \mathrm{m}$ deep holes. Whenever the machining force exceeded $0.4 \mathrm{~N}$, the tool was moved upwards until the force disappeared and was then moved further upwards by a gap of $10 \mu \mathrm{m}$. A waiting time, called flushing time, was finally added to evacuate the machining zone.

\subsection{Enhancing the Flushing While Maintaining Heating by Applying Tool Vibrations}

Based on the outcome from the previous experiments, the need arose for a method to flush the machining zone while keeping the generated heat by the discharges as close as possible to the work-piece. For this purpose, tool vibrations were applied. As was performed with the previous experiments, whenever a force above a certain preset threshold was detected while machining, the tool was moved upwards until the force became null. The tool was then moved upwards by a certain gap and vibrations were applied. In this case, one-sided vibrations, in the downward direction, having $8 \mu \mathrm{m}$ amplitude were applied to the tool once a gap of $7 \mu \mathrm{m}$ was created in order to force the tool to contact the glass surface during each vibration (Figure 5a). Therefore, for this algorithm a counter-action means moving the tool upwards whenever a force higher than the threshold is detected until this force is reduced to zero, then creating a $7 \mu \mathrm{m}$ gap and applying $8 \mu \mathrm{m}$ amplitude vibrations (downward direction). Different number of vibrations and vibration frequencies per counter-action were investigated, and the results are presented as Test 1 to Test 5 in Figure 5b. 
a)

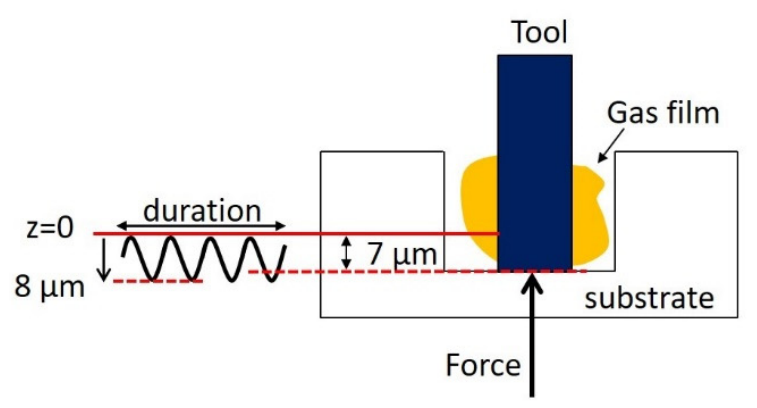

b)

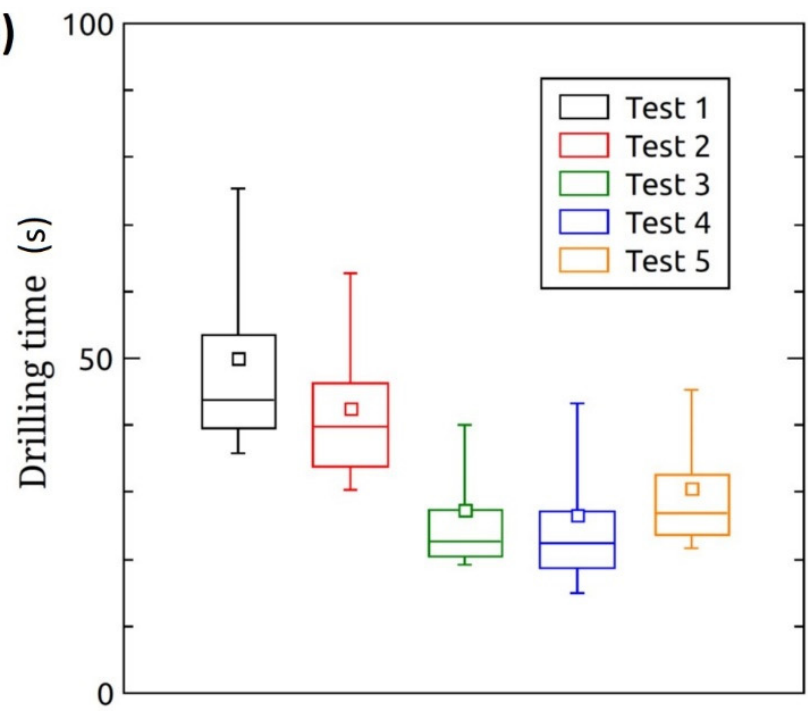

Figure 5. (a) The vibration signal applied on the tool during a counter-action; (b) the drilling time when applying vibrations during different time duration. A counter-action refers to applying $8 \mu \mathrm{m}$ amplitude vibrations in the downward direction when a certain force threshold is exceeded but only after the force is recovered and a gap of $7 \mu \mathrm{m}$ is created. Slow vibrations ( $0.1 \mathrm{~s}$ period) were applied during $1 \mathrm{~s}$ (10 vibrations) and $0.2 \mathrm{~s}$ ( 2 vibrations), respectively (Tests 1 and 2 ), when $0.8 \mathrm{~N}$ force was exceeded. For Tests 3,4 and 5 quick vibrations ( $0.02 \mathrm{~s}$ period) were applied during $0.2 \mathrm{~s}$ (10 vibrations) when the force exceeded $0.8 \mathrm{~N}, 0.4 \mathrm{~N}$ and $0.2 \mathrm{~N}$, respectively. The $250 \mu \mathrm{m}$ deep holes were drilled in $30 \mathrm{wt} \% \mathrm{NaOH}$ solution while applying $30 \mathrm{~V}$ and $50 \mu \mathrm{m} / \mathrm{s}$.

In Test 1 , ten successive vibrations were applied during $1 \mathrm{~s}$ per counter-action (thus vibration period was $0.1 \mathrm{~s}$ ) and the force threshold was $0.8 \mathrm{~N}$. In Test 2, the number of vibrations per counter-action was reduced to two applied vibrations during $0.2 \mathrm{~s}$, hence keeping the same vibration frequency as Test 1 , and a shorter drilling time resulted. This shows that applying vibrations during a longer time does not enhance flushing, but rather decelerates the machining speed. This outcome may be explained by the fact that more vibration time means better flushing but reduced surface temperature due to more heat loss. Therefore, in Test 3 more vibrations were applied per counter-action but during a shorter time (10 vibrations during $0.2 \mathrm{~s}$ implying that a single vibration period is $0.02 \mathrm{~s}$ ) to maintain the local heating caused by frequent tool-glass contact. The drilling time was reduced by $15 \mathrm{~s}$ compared to Test 2 (two vibrations during $0.2 \mathrm{~s}$; vibration period of $0.1 \mathrm{~s}$ ) although the total counter-action vibration duration was the same $(0.2 \mathrm{~s})$ in both cases. This proves that the high vibration frequency (frequency of tool-glass contact) indeed is crucial to the process. In this case heating is accompanied with flushing duration of $0.2 \mathrm{~s}$.

Upon comparing the drilling time of Test 3 and Test 1 where 10 vibrations were applied during $0.2 \mathrm{~s}$ and $1 \mathrm{~s}$, respectively, the number of total counter-actions carried out per hole was the same for both tests. In fact, it turns out that the difference in drilling time between the two tests is the time needed to perform the counter-actions (e.g., 20 counter-actions will take around $20 \mathrm{~s}$ for Test 1 versus around $4 \mathrm{~s}$ for Test 3 resulting in a time difference of $16 \mathrm{~s}$ ). Therefore, applying a longer flushing time per counter-action ( $1 \mathrm{~s}$ versus $0.2 \mathrm{~s}$ ) did not have an effect on the local flushing in the case of a high force threshold of $0.8 \mathrm{~N}$. On the other hand, increasing the frequency of vibrations from 2 to 10 vibrations per counter-action applied during a relatively low flushing time of $0.2 \mathrm{~s}$ (i.e., Test 2 versus Test 3 ) helps reduce the drilling time by improving flushing while maintaining local heating. Hence, tool vibrations have to be carefully applied to accelerate drilling.

To ensure that the effect of vibration frequency is not opposed by the high force threshold chosen, two more tests were conducted where the force threshold was lowered to $0.4 \mathrm{~N}$ (Test 4 ) and $0.2 \mathrm{~N}$ (Test 5). For these two tests 10 vibrations were applied during $0.2 \mathrm{~s}$ per counter-action (vibration period of $0.02 \mathrm{~s}$ ). Results showed that the drilling time was slightly reduced for Test 4 whereas it increased again for Test 5 . This can be explained 
by the less efficient heating of the machining zone when a very low force threshold $(0.2 \mathrm{~N}$ in this case) is used, as shown in Section 3.1. Therefore, a medium force threshold of $0.4 \mathrm{~N}$ showed the best results.

\subsection{Enhancing Flushing While Maintaining Heating by Adding Tool Vibration and Rotation}

The results of the previous section show that appropriate application of tool vibrations result in local electrolyte flow in the vertical direction. In order to add local fluid motion in the radial direction the tool is additionally rotated. Holes, $500 \mu \mathrm{m}$ in depth which is almost twice the depth at which the hydrodynamic regime starts, were drilled in less viscous electrolyte $(50 \mathrm{wt} \% \mathrm{KOH})$ while applying $30 \mathrm{~V}$ and a rotation speed of $1000 \mathrm{rpm}$. The rotation speed was chosen to be moderate such that it would allow local electrolyte flow while not interrupting discharge activity (due to gas film instability at high speeds) for the tool size used. Whenever a force threshold of $0.4 \mathrm{~N}$ was exceeded, a counter-action was carried out. The force threshold of $0.4 \mathrm{~N}$ was chosen based on the outcome of the previous algorithm. Here, a counter-action refers to moving the tool upwards whenever a force threshold of $0.4 \mathrm{~N}$ is exceeded until the force becomes null, then creating a gap of $7 \mu \mathrm{m}$, and rotating the tool at $1000 \mathrm{rpm}$. Results show that drilling time was about $27 \mathrm{~s}$. When the tool was both rotated and vibrated (10 fast vibrations applied during $0.2 \mathrm{~s}$, vibration period of $0.02 \mathrm{~s}$ ) the drilling time was further reduced (average of $20 \mathrm{~s}$ ) as shown in Figure 6. This result shows that by applying both tool rotation and vibration the drilling time is further reduced compared to the case of applying either tool rotation or vibration (Figure $5 b$ ). When applying solely vibration or rotation a drilling time above $25 \mathrm{~s}$ results.

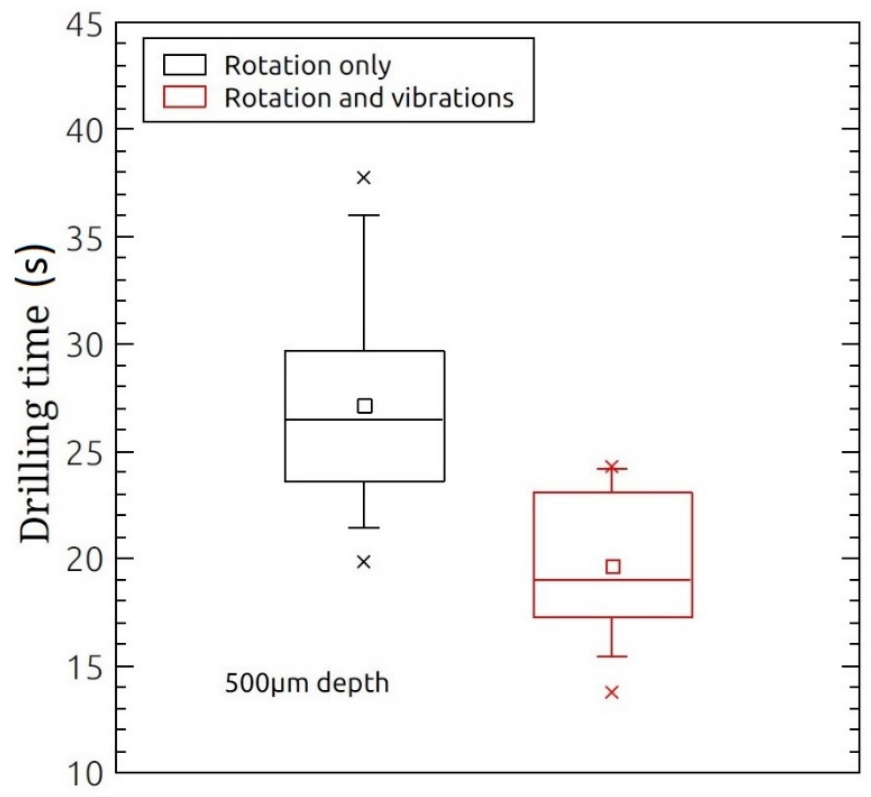

Figure 6. The drilling time when applying solely tool rotation (case 1) and tool rotation with vibration (case 2) when the machining force exceeded $0.4 \mathrm{~N}$. A counter-action in case 1 means moving the tool upwards until the machining force became null, creating a gap of $7 \mu \mathrm{m}$ and adding $1000 \mathrm{rpm}$ tool rotation. In case 2 , the counter-action also involved applying fast vibrations $(0.02 \mathrm{~s}$ period, $8 \mu \mathrm{m}$ amplitude) during $0.2 \mathrm{~s}$ (10 vibrations). The $500 \mu \mathrm{m}$ deep holes were drilled in $50 \mathrm{wt} \% \mathrm{KOH}$ solution while applying $30 \mathrm{~V}, 50 \mu \mathrm{m} / \mathrm{s}$ tool feed-rate and $1000 \mathrm{rpm}$ rotational speed.

\section{Conclusions}

This work shows trends that further the understanding about the fundamentals of the SACE machining process. The effect of each of heating and flushing on the machining progress, measured in terms of drilling time, was separately studied through designing and applying specific tool motion algorithms. This work gives more insight about the SACE 
process, hence allowing enhancement of SACE machining capabilities. The following conclusions are drawn:

- Allowing tool-substrate contact while machining helps reduce drilling time through enhanced local heating. However, the force threshold should be carefully chosen. Moderate force threshold showed the best results.

- Creating a tool-surface gap whenever the tool-substrate contact force threshold is exceeded helps local flushing given that adequate time is allowed for that.

- Adding tool vibrations on top of creating a gap whenever the tool-substrate contact force threshold is exceeded helps to flush the hole while maintaining close contact between tool and substrate. High frequency vibrations are of particular interest as they result in further reducing drilling time.

- Adding tool rotation when the contact force threshold is exceeded and after establishing a gap has a similar effect as adding high frequency tool vibrations. However, when both rotation and vibration are applied drilling time is further reduced due to the combined effect of heating and local flow enhancement.

Author Contributions: Conceptualization, J.D.A.Z.; methodology, J.D.A.Z. and R.W.; software, J.D.A.Z.; validation J.D.A.Z.; formal analysis, J.D.A.Z.; investigation, J.D.A.Z.; resources, J.D.A.Z.; data curation, J.D.A.Z. and R.W.; writing-original draft preparation, J.D.A.Z.; writing-review and editing, J.D.A.Z. and R.W.; visualization, J.D.A.Z.; supervision, J.D.A.Z. and R.W.; project administration, J.D.A.Z.; funding acquisition, J.D.A.Z. All authors have read and agreed to the published version of the manuscript.

Funding: This research was funded by the Natural Sciences and Engineering Research Council of Canada (NSERC) Discovery Grant program.

Institutional Review Board Statement: Not applicable.

Informed Consent Statement: Not applicable.

Conflicts of Interest: The authors declare no conflict of interest.

\section{References}

1. Kellogg, H.H. Anode Effect in Aqueous Electrolysis. J. Electrochem. Soc. 1950, 97, 133. [CrossRef]

2. Reghuram, V. Electrical and Spectroscopic Investigations in Electrochemical Discharge Machining. Ph.D. Thesis, Indian Institute of Technology, Madras, India, 1994.

3. Jalali, M.; Maillard, P.; Wüthrich, R. Toward a better understanding of glass gravity-feed micro-hole drilling with electrochemical discharges. J. Micromech. Microeng. 2009, 19, 45001-45008. [CrossRef]

4. Abou Ziki, J.D.; Hof, L.A.; Wüthrich, R. The machining temperature during Spark Assisted Chemical Engraving of glass. Manuf. Lett. 2015, 3, 9-13. [CrossRef]

5. Wüthrich, R.; Spaelter, U.; Wu, Y.; Bleuler, H. A systematic characterization method for gravity-feed micro-hole drilling in glass with spark assisted chemical engraving (SACE). J. Micromech. Microeng. 2006, 16, 1891-1896. [CrossRef]

6. Abou Ziki, J.D.; Wüthrich, R. The machining gap during constant velocity-feed glass micro-drilling by Spark Assisted Chemical Engraving. J. Manuf. Process. 2015, 19, 87-94. [CrossRef]

7. Zheng, Z.-P.; Su, H.-C.; Huang, F.-Y.; Yan, B.-H. The tool geometrical shape and pulse-off time of pulse voltage effects in a Pyrex glass electrochemical discharge microdrilling process. J. Micromech. Microeng. 2007, 17, 265-272. [CrossRef]

8. Tang, W.; Kang, X.; Zhao, W. Enhancement of electrochemical discharge machining accuracy and surface integrity using side-insulated tool electrode with diamond coating. J. Micromech. Microeng. 2017, 27, 065013. [CrossRef]

9. Paul, L.; Jose, I. Micro Machining in ECDM Process with Tool Modification. Mater. Today Proc. 2018, 5, 11875-11881. [CrossRef]

10. Ranganayakulu, J.; Srihari, P.V. Investigations on the effect of helical tool diameter assisted with high speed rotation in electrochemical discharge machining. Int. J. Precis. Technol. 2021, 10, 60-73. [CrossRef]

11. Zhang, Y.; Xu, Z.; Zhu, Y.; Zhu, D. Effect of tube-electrode inner structure on machining performance in tube-electrode high-speed electrochemical discharge drilling. J. Mater. Process. Technol. 2016, 231, 38-49. [CrossRef]

12. Yang, C.-K.; Wu, K.-L.; Hung, J.-C.; Lee, S.-M.; Lin, J.-C.; Yan, B.-H. Enhancement of ECDM efficiency and accuracy by spherical tool electrode. Int. J. Mach. Tools Manuf. 2011, 51, 528-535. [CrossRef]

13. Kim, D.J.; Ahn, Y.; Lee, S.H.; Kim, Y.K. Voltage pulse frequency and duty ratio effects in an electrochemical discharge microdrilling process of Pyrex glass. Int. J. Mach. Tools Manuf. 2006, 46, 1064-1067. [CrossRef]

14. Zheng, Z.P.; Lin, J.K.; Huang, F.Y.; Yan, B.H. 2008. Improving the machining efficiency in electrochemical discharge ma-chining (ECDM) microhole drilling by offset pulse voltage. J. Micromech. Microeng. 2008, 18, 025014. [CrossRef] 
15. Rajput, V.; Goud, M.; Suri, N.M. Performance Analysis of ECDM Process Using Surfactant Mixed Electrolyte. In Manufacturing Engineering; Springer: Berlin/Heidelberg, Germany, 2020; pp. 285-300. [CrossRef]

16. Vemula, V.V.; Chak, S.K. Effect of loose abrasive mixed electrolyte on the aspect ratio of blind holes drilled in soda-lime glass by ECDM process. Manuf. Rev. 2020, 7, 37. [CrossRef]

17. Ho, C.-C.; Chen, J.-C. Micro-Drilling of Sapphire Using Electro Chemical Discharge Machining. Micromachines 2020, $11,377$. [CrossRef] [PubMed]

18. Gautam, N.; Jain, V.K. Experimental investigations into ECSD process using various tool kinematics. Int. J. Mach. Tools Manuf. 1998, 38, 15-27. [CrossRef]

19. Lee, E.S.; Howard, D.; Liang, E.; Collins, S.; Smith, R. Removable tubing interconnects for glass-based micro-fluidic systems made using ECDM. J. Micromech. Microeng. 2004, 14, 535-541. [CrossRef]

20. Han, M.S.; Min, B.K.; Lee, S.J. Geometric improvement of electrochemical discharge micro-drilling using an ultrasonic-vibrated electrolyte. J. Micromech. Microeng. 2009, 19, 065004. [CrossRef]

21. Cheng, C.-P.; Wu, K.-L.; Mai, C.-C.; Hsu, Y.-S.; Yan, B.-H. Magnetic field-assisted electrochemical discharge machining. J. Micromech. Microeng. 2010, 20, 075019. [CrossRef]

22. Xu, Y.; Chen, J.; Jiang, B.; Liu, Y.; Ni, J. Experimental investigation of magnetohydrodynamic effect in electrochemi-cal discharge machining. Int. J. Mech. Sci. 2018, 142, 86-96. [CrossRef]

23. Arya, R.K.; Dvivedi, A. Investigations on quantification and replenishment of vaporized electrolyte during deep micro-holes drilling using pressurized flow-ECDM process. J. Mater. Process. Technol. 2019, 266, 217-229. [CrossRef]

24. Xu, Y.; Chen, J.; Jiang, B.; Ni, J. Investigation of micro-drilling using electrochemical discharge machining with counter resistant feeding. J. Mater. Process. Technol. 2018, 257, 141-147. [CrossRef]

25. Cao, X.D.; Kim, B.H.; Chu, C.N. Micro-structuring of glass with features less than $100 \mu \mathrm{m}$ by Electrochemical Discharge Machining. Precis. Eng. 2009, 33, 459-465. [CrossRef]

26. Abou Ziki, J.D.; Wüthrich, R. Forces exerted on the tool-electrode during constant-feed glass micro-drilling by spark assisted chemical engraving. Int. J. Mach. Tools Manuf. 2013, 73, 47-54. [CrossRef] 